\title{
Two decades of nutrition assessment in the Eastern Mediterranean Region: scope, methodologies and dissemination
}

W.A. Moussa ${ }^{1}$

\begin{abstract}
SUMMARY Different nutritional disorders prevail at different stages in the life cycle, e.g. growth retardation in the fetus, protein energy deficiency in children, noncommunicable conditions in adults. The scope of nutrition assessment has changed over the past 2 decades. The focus shifted from pregnant and lactating mothers and children, through functional consequences of malnutrition to deficiency disorders. Now the focus is on obesity. Clinical methods of assessment (usually indicators of late-stage malnutrition) have become less important recently although clinical indicators of iodine deficiency and vitamin A deficiency are still useful. The key method now is anthropomorphic measurement, such as weight-for-age or body mass index. All the countries of the Region have nutrition education programmes for dissemination of information and most have drawn up national dietary guidelines applying the strategies that were developed after the 1992 International Conference on Nutrition.
\end{abstract}

\section{Introduction}

According to the global burden of disease concept, the disability adjusted life year (DALY) expresses years of life lost due to premature death and years lived with a disability of a specified severity and duration. One DALY is thus 1 year of healthy life lost [1]. In the list of main risk factors contributing to the global burden of disease, malnutrition was top, contributing $15.9 \%$ of total DALYs [1]. The burden of disease (expressed as DALYs) by cause, sex and mortality stratum has been estimated by the World Health Organization for each region for the year 2002 [2]. The total for DALYs due to nutritional deficiencies in the Eastern Mediterranean Region was 631 in the low child low adult mortality stratum countries and 3798 in the high child high adult mortality stratum countries [2].

Malnutrition was the direct or the underlying cause of death of $49 \%$ of children under 5 years in developing counties during 1995 [3]. The burden of mortality, morbidity and disability attributable to noncommunicable diseases now weighs heaviest in developing countries, where those affected are on average younger than in the industrialized countries. Unhealthy diets and physical inactivity were found to be the leading causes of the major noncommunicable diseases [4].

The negative impact of malnutrition on body functions has been extensively studied all over the world. In the Eastern Mediterranean Region, a prominent longitudinal study implemented in Egypt during 1982- 
1987 documented the effect of food intake on cognitive function, social behaviour, work performance, immunocompetence and reproductive health $[5,6]$.

It is therefore important to assess nutritional status and establish the main determinants for both individuals and the community. This will provide tools for the prevention, early detection, management and control of nutrition disorders.

Key objectives of nutrition assessment in the Region can be summarized under 6 main topics:

- to identify high-risk groups and geographical areas with nutrition-related problems to facilitate implementation of public health intervention programmes;

- to recommend guidelines for the prevention, early detection and management of nutrition disorders;

- to study diet-health relationships and the impact of knowledge and attitudes toward dietary and health behaviour;

- to develop nutrition education and dietary guidance e.g. national food-based dietary guidelines [7];

- to assess progress toward achieving the nutrition and health objectives, e.g. the plan of action for nutrition promoted by the International Conference on Nutrition, Rome, 5-11 December 1992 [8];

- to monitor and evaluate nutrition intervention programmes.

\section{Scope}

Nutrition assessment done in the Region includes methodologies that deal with the nutritional disorders prevailing at different stages in the life cycle. These conditions can be summarized according to the life stage.
Fetal development within the maternal environment and neonatal period

- Intrauterine growth retardation leading to low birth weight of the neonate and growth retardation during infancy $[9,10]$;

- iodine deficiency disorders, which may lead to developmental retardation and brain damage or stillbirths;

- folate deficiency among pregnant mothers may lead to neural tube defects on the neonate (in most counties of the Region, $400 \mu \mathrm{g} /$ day folic acid is given as a supplement to pregnant mothers together with iron pills).

Recently, there has been considerable evidence, mostly from industrialized countries, that intrauterine growth retardation followed by very rapid postnatal catch-up growth is associated with an increased risk of coronary heart disease, stroke, diabetes and raised blood pressure [11-13]. On the other hand, large size at birth (macrosomia) is also associated with increased risk of diabetes and cardiovascular disease $[14,15]$.

It is worth stating that as a result of industrialization, urbanization, economic development and market globalization in most countries of the Region, there have been changes in dietary and lifestyle patterns leading to the emergence of obesity and diet-related, chronic, noncommunicable diseases, which are taking over from the more traditional undernutrition and infectious diseases as causes of morbidity and mortality $[16-21]$.

Infants and young children [22-28]

- Protein-energy malnutrition;

- iodine deficiency disorders; 
- vitamin A deficiency and vitamin A deficiency disorders;

- iron deficiency anaemia.

These disorders may lead to stunting, developmental retardation, e.g. low cognitive performance, increased risk of infection and high risk of death.

\section{Adolescents and preadolescents [16,18,19,29-34]}

- Protein-energy malnutrition, iodine deficiency disorders and iron deficiency anaemia, with similar consequences to the previous stage;

- calcium deficiency, leading to inadequate bone mineralization with possible osteoporosis during adulthood;

- obesity, which may continue during adulthood with higher risk for all associated co-morbidities, particularly cardiovascular disease and type II diabetes.

\section{Pregnant and lactating women [25, 35-38]}

- Protein-energy malnutrition, iodine deficiency disorders, vitamin A deficiency and iron deficiency anaemia;

- folate deficiency;

- calcium deficiency.

Apart from the above-listed sequelae, these disorders may lead to insufficient weight gain during pregnancy, low-birthweight babies and increased risk of maternal mortality.

\section{Adults [18,19,39-43]}

- Protein-energy malnutrition and iron deficiency anaemia;

- obesity;

- diet-related, chronic, noncommunicable diseases, e.g. coronary heart disease, hypertension/stroke, diabetes and osteoporosis.
Thinness and chronic energy deficiency among adults as a result of protein-energy malnutrition are very rare in the Region apart from a few countries in the high child high adult mortality stratum.

\section{The elderly [44]}

- Protein-energy malnutrition, iron deficiency anaemia, obesity, osteoporosis and diet-related chronic diseases.

\section{Scope of assessment in the Region}

The scope of nutrition assessment in the Region has changed within the last 2 decades. At the beginning of the $1980 \mathrm{~s}$, the focus was on pregnant and lactating mothers and children under 2 or under 5 years. Main problems assessed were proteinenergy malnutrition, iron deficiency anaemia, breastfeeding and weaning practices. Functional consequences of malnutrition were investigated in Egypt during the 1980s.

Iodine deficiency disorders and vitamin A deficiency emerged as the focus of nutrition assessment in the Region in the 1990s $[45,46]$. The goals of the World Summit for Children, New York, 29-30 September 1990 , and the plan of action from the International Conference on Nutrition, Rome, 5-11 December 1992 were the initiators to focusing on micronutrient malnutrition in the Region $[47,48]$.

With the nutrition transition in most countries of the Region, the problem of obesity and comorbidities among adults and adolescents attracted the attention of the nutrition investigators in the 1990s and this has continued to the present. With the beginning of the third millennium, diet and lifestyle-related problems like osteoporosis among adults and the elderly were also investigated within the scope of nutrition assessment [19]. 
Nutrition assessment methodologies commonly used in the Eastern Mediterranean Region

Nutrition and health assessment of the individual and the community

These include:

- anthropometric measurements, mainly weight, stature, arm circumference, waist circumference, waist-to-hip ratio, skin fold thickness (commonly at triceps) $[49,50]$;

- clinical assessment, mainly by signs of deficiency and medical history [51-55];

- laboratory investigations; measurements of nutrients or their metabolites in biological fluids and comparison with reference standards and cut-off points [52,54,56-59];

- biophysical investigations e.g. X-ray for rickets, and dual-energy X-ray absorptiometry for assessment of bone mass density used to determine prevalence of osteoporosis $[60,19]$.

The dark adaptation test for vitamin A deficiency is not used in the Region.

\section{Assessment of the main determinants of nutritional status of the individual and the community}

These include:

- food availability at the national level measured by the food balance sheet (available through the Food and Agriculture Organization and national ministries of agriculture);

- household food security and food intake of the individual, measured by dietary assessment methods;

- breastfeeding, weaning practices and weaning foods, which are extensively studied in the Region [61-68];
- morbidity status e.g. infection, infestations or chronic noncommunicable diseases [69];

- social, economic and cultural factors such as education, occupation, income, habits, beliefs and lifestyle, e.g. physical activity;

- availability and utilization of health, nutrition and social services and caring capacity at the community and household level [70,71];

- biodemographic factors, mainly age, sex, family size, interpregnancy interval, physiological status, e.g. pregnant or lactating.

All these determinants are assessed through prestructured questionnaires or rapid assessment procedures and focus group discussions. Observation methods at the household level are not culturally accepted in the Region; for instance, observation and weighing methods for dietary assessment could not be applied in Egypt [72]. The most commonly used dietary assessment methods are food frequency, to describe dietary pattern, and 24-hour recall or 24-hour recall and sample weighing, to determine dietary adequacy. Food intake in household measures is converted to grams and then to energy, macronutrients and micronutrients, which are compared with recommended dietary allowances [72-75]. Caring capacity and physical activity are assessed by questionnaire for time allocation rather than observation $[17,70]$.

In the Eastern Mediterranean Region, the key method for assessment of nutritional status is anthropometric measurement, mainly weight and stature of the individual in the community. At the beginning of the last 2 decades, the focus was on anthropometric measurement of children under 5 years as an indicator of the nutritional status of the whole community. In- 
terpretation of weight and stature measurements was mainly based on the Gomez classification, then the Waterlow classification using reference standards for weightfor-age, weight-for-height and heightfor-age $[76,77]$.

In 1983, the World Health Organization recommended using standard deviation (SD) scores for classifying children under 18 years into underweight, normal or overweight, and stunted, normal or tall children according to certain cut-off points: $<-2$ SDs, -2 to +2 SDs and $>+2$ SDs respectively from the reference median [49].

In 1995, body mass index (BMI, weight $(\mathrm{kg}) /$ height $^{2}\left(\mathrm{~m}^{2}\right)$ was recommended for use in adults to differentiate between normal weight, 3 grades of chronic energy deficiency (or underweight) and 3 grades of obesity [50]. In 2000, the obesity classification was modified into pre-obese (BMI 25.0-29.9 kg/m²), obese class I (BMI $30.0-34.9 \mathrm{~kg} / \mathrm{m}^{2}$ ), obese class II (BMI $35.0-39.9 \mathrm{~kg} / \mathrm{m}^{2}$ ) and obese class III (BMI $\geq 40.0 \mathrm{~kg} / \mathrm{m}^{2}$ ) [78]. The Garrow classification [79] was used to describe weight status of adults before 1995 .

In 1995, the World Health Organization recommended the use of percentile BMI for age for adolescents 10-19 years to differentiate underweight $(<5$ th percentile), normal ( 5 th $-<85$ th percentile), overweight $(85$ th $-<95$ th percentile) and obese ( $\geq 95$ th percentile) [50].

Clinical assessment for nutrition disorders has almost lost its value in the last 2 decades. Clinical signs of malnutrition are usually late signs, thus identifying severe cases of malnutrition. In most countries of the Region, malnutrition is usually mild to moderate, thus mainly detected by anthropometric, biochemical or haematological methods. The clinical signs still of value are those for iodine deficiency disorders and vitamin A deficiency [52,54]. In most countries of the Region, however, vitamin A deficiency is detected by serum retinol $<20 \mu \mathrm{g} / \mathrm{dL}$ and rarely by night blindness or Bitot's spots [59]. For iodine deficiency disorders, grades of goitre and urinary iodine are the most commonly used signs [52]. For iron deficiency anaemia, haemoglobin determination, and to a lesser extent serum ferretin, are the indicators most commonly used [56].

Recently, with the problem of obesity and co-morbidities emerging in the Region, blood glucose, total serum cholesterol and low-density lipoprotein cholesterol are measured [80].

Some sophisticated biochemical measurements are carried out for study of certain specialized problems, such as osteoporosis in Egypt [19].

In the Eastern Mediterranean Region, the approach for assessment is nutrition surveys rather than nutrition surveillance. All 22 countries have had national surveys within the past 2 decades, covering all the nutrition problems detected in the Region along with their main determinants (as discussed under "Scope") [81-106].

There have been efforts to establish nutrition monitoring or nutrition surveillance systems in many countries of the Region $[80,106]$. Strengthening of these efforts is, however, still required. Surveillance efforts are based mainly on the primary health care system, using growth monitoring and promotion of children under-5 as the core of the system. Most of the growth charts used in the Region are based on the World Health Organization model using percentiles of the American National Center for Health Statistics reference standards. In Egypt, the national growth chart simply consists of 2 curves, +2 SDs and -2 SDs of the NCHS reference standard of weightfor-age for boys and girls under 6 . 


\section{Dissemination}

During the past 2 decades, extensive nutrition assessment studies have been conducted in all countries of the Region. The main nutrition problems and risk factors have been identified. Population groups and geographic areas most at risk for each nutrition disorder in each country were determined. The wealth of information generated from these studies was disseminated to policy-makers to formulate strategies for prevention and control. Information was also disseminated to the scientific community through workshops, seminars, conferences and published papers.

Dissemination of simplified information to the public is the cornerstone of the promotion of health and nutritional status and the prevention of malnutrition. All the countries of the Region had enthusiastic nutrition education programmes applying all possible methods and vehicles appropriate to local conditions.

Activities using the information generated from nutrition assessment reached their peak at the beginning of the 1990s during the preparations for the international conference in Rome. Almost all countries of the Region submitted papers describing in detail nutrition problems and the immediate, underlying and basic factors leading to these problems, along with intervention programmes that were operating $[8,22]$.
National and Regional workshops were conducted during the preconference consultation process. After the conference in December 1992 [8], almost every country of the Region prepared a plan of action on nutrition based on 9 action-oriented strategies [107]. These strategies constitute the framework of nutrition information disseminated to the different sectors of the population in the Region. They are:

- incorporating nutritional objectives, considerations and components into development policies and programmes;

- improving household food security;

- protecting consumers through improved food quality and safety;

- preventing and managing infectious diseases;

- promoting breastfeeding;

- caring for the socioeconomically deprived and the nutritionally vulnerable;

- preventing and controlling specific micronutrient deficiencies;

- promoting appropriate diets and healthy lifestyles;

- assessing, analysing and monitoring nutrition situations.

Most countries of the Region have prepared, or are in the process of preparing, national food-based dietary guidelines applying these strategies through a simplified and practical approach for the public.

\section{References}

1. Murray CJL, Lopez AD, eds. The global burden of disease (summary). Geneva, World Health Organization, Harvard School of Public Health \& World Bank, 1996.

2. The world health report 2003 - shaping the future. Geneva, World Health Organization, 2003.
3. Nutrition for health and development: progress and prospects on the eve of the 21st century. Geneva, World Health Organization, 1999 (WHO/NHD/99.9).

4. The world health report 2002 - reducing risks, promoting healthy life. Geneva, World Health Organization, 2002. 
5. Galal $\mathrm{O}$ et al. The collaborative research support program on food intake and human function. Final report to USAID. Berkeley, University of California, 1987 (Grant No. Dan-1309-G-SS-1070-00).

6. Callaway DH, Murphy SP, Beaton GH. Food intake and human function: a cross project perspective of the collaborative research support program in Egypt, Kenya and Mexico. Berkeley, University of California, 1988.

7. Preparation and use of food-based dietary guidelines. Report of a joint FAO/ WHO consultation. Geneva, World Health Organization, 1998 (WHO Technical Report Series, No. 880).

8. World declaration and plan of action for nutrition. Resolution adopted by the International Conference on Nutrition, Rome, 5-11 December 1992 (Resolution WHA 46.7).

9. Abdel Ghany SA. Maternal nutrition and outcome of pregnancy [thesis]. Cairo, University of Helwan, 1986.

10. El Agroudy AA. Fetal malnutrition among pregnant adolescents [thesis]. Cairo, University of Helwan, 1989.

11. Eriksson JG et al. Catch-up growth in childhood and death from coronary heart disease: longitudinal study. British medical journal, 1999, 318(7181):42731.

12. Godfrey KM, Barker DJ. Fetal nutrition and adult disease. American journal of clinical nutrition, 2000, 71(5 suppl.): S1344-52.

13. Programming of chronic disease by impaired fetal nutrition: evidence and implications for policy and intervention strategies. Geneva, World Health Organization, 2002 (WHO/NHD/02.3 \& WHO/ $\mathrm{NPH} / 02.1)$.

14. Rich-Edwards JW et al. Birth weight and risk of type 2 diabetes mellitus in adult women. Annals of internal medicine, 1999, 130(4 pt. 1):278-84.

15. Forsen $T$ et al. Growth in utero and during childhood in women who develop coronary heart disease: longitudinal study. British medical journal, 1999, 319(7222):1403-7.

16. Musaygar AU and Mistry N. Obesity in the Arab Gulf countries: an annotated bibliography. Bahrain, Bahrain Center for Studies and Research, 2001.

17. Hussein $\mathrm{M}$ et al. Sociocultural and dietary factors that predispose to obesity and morbidity consequences. Final report. Cairo, National Institute of Nutrition \& World Health Organization, 1993.

18. Shaheen F et al. Prevalence of obesity in Egypt. National survey, final report. Cairo, National Nutrition Institute, 2004.

19. Hassan H, Abdel Galil A, Moussa W. National survey for the determination of bone mass density among adolescents and adults in Egypt. Final report. Cairo, National Nutrition Institute, 2004.

20. Herman WH et al. Diabetes mellitus in Egypt: risk factors and prevalence. Diabetic medicine, 1995, 12(12):1126-31.

21. Ibrahim MM et al. Hypertension prevalence, awareness, treatment and control in Egypt. Results from the Egyptian national hypertension project. Hypertension, 1995, 26(6):886-90.

22. Summary of the international conference on nutrition (ICN). Country papers. Cairo, Food and Agriculture Organization Regional Office for the Near East, 1993 (92-855-6022-9).

23. Nutrition country profiles for selected countries of the Near East Region. Cairo, Food and Agriculture Organization Regional Office for the Near East, 1995.

24. Hassan $\mathrm{H}$ et al. Egypt nutrition country profile. Cairo, Egypt, National Institute of 
Nutrition \& Food and Agriculture Organization Regional Office for the Near East, 2001.

25. Moussa W et al. Vitamin A status in Egypt. In: Proceedings of the XVIII IVACG meeting, Cairo, Egypt, 22-26 September 1997. Washington DC, International Life Sciences Institute, 1997.

26. Amine EK. Bahrain nutrition status survey. Abu Dhabi, United Nations Children's Fund Gulf Area Office, 1980.

27. Amine EK. Oman nutrition status survey. Abu Dhabi, United Nations Children's Fund Gulf Area Office, 1980.

28. Osman AK. Nutrition status survey, United Arab Emirates. Abu Dhabi, United Nations Children's Fund Gulf Area Office, 1981.

29. Aly HE et al. Anthropometric measurements of Cairo schoolchildren: a followup study. Journal of the Egyptian Public Health Association, 1980, 55:143-65.

30. Habib N. Teenage obesity among preparatory schools in Ismailia [thesis]. Ismailia, Suez Canal University, 1987.

31. Hussein MA et al. Prevalence of iodine deficiency disorders among school children in Egypt. Final report. Cairo, National Institute of Nutrition \& World Health Organization, 1992.

32. Hassan HA. Nutritional deficiencies among primary school children in Egypt, final report. Cairo, National Institute of Nutrition \& World Health Organization, 1998.

33. Swaiffy EM. Effect of nutritional status on some psychosocial parameters in primary school children [thesis]. Cairo, University of Helwan, 1987.

34. Eid $\mathrm{N}$ et al. Anemia in school children in Kuwait. A preliminary study. Journal of the Kuwait Medical Association, 1986, 20:39.
35. Smart IS, Duncan ME, Kalina JM. Hemoglobin levels and anemia in pregnant Saudi women. Saudi medical journal, 1983, 4:263.

36. Davidson R. Hemoglobin values in preschool children and pregnant women in Oman. Medical newsletter, 1986, 2:38.

37. Dawood JS, Prakash P, Shubler KM. Iron deficiency anemia among pregnant Arab women. Journal of the Kuwait Medical Association, 1990, 24:167.

38. Verster A, Van der Pols JC. Anaemia in the Eastern Mediterranean Region. Eastern Mediterranean health journal, 1995, 1(1):64-79.

39. Al-Awadi F, Amine E. Overweight and obesity in Kuwait. Journal of the Royal Society of Health, 1989, 109(5):175-7.

40. Amine EK, al-Awadi FA, Goulam Z. Underweight and obesity among adult males in Kuwait. Journal of the Medical Research Institute, 1993, 14(6):293315.

41. Musaiger AO. Health and nutritional status of Omani families. Muscat, Oman, United Nations Children's Fund, 1992.

42. Alwan $\mathrm{A}$, King $\mathrm{H}$. Diabetes in the Eastern Mediterranean region. World health statistics quarterly, 1992, 45(4):355-9.

43. Musaiger AO et al. Dietary and social factors associated with myocardial infarction in Bahrain. Bahrain, Arabian Gulf University, 1993.

44. Hassan HA et al. Focusing on the health requirements and style of living to improve the health of elderly people in different cultural sectors in Egypt, final report. Cairo, National Institute of Nutrition \& National Academy of Science and Technology, 2001.

45. World Health Organization, United $\mathrm{Na}$ tions Children's Fund, International

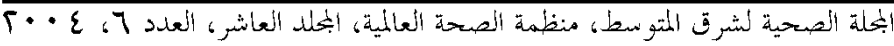


Council for the Control of lodine Deficiency Disorders. Global prevalence of iodine deficiency disorders. Geneva, World Health Organization, 1993 (MDIS working paper No. 1).

46. Global prevalence of vitamin A deficiency: micronutrient deficiency information system. Geneva, World Health Organization, 1995 (MDIS working paper No. 2).

47. World declaration and plan of action on the survival, protection and development of children. Adopted at the World Summit for Children, New York, 29-30 September 1990. New York, United Nations Children Fund, 1990.

48. Preventing specific micronutrient deficiencies, major issues for nutrition strategies. Theme paper No. 6, International conference on nutrition, Rome, 5-11 December 1992. Rome, Food and Agriculture Organization \& World Health Organization, 1992.

49. Measuring change in nutritional status. Guidelines for assessing the nutritional impact of supplementary feeding programmes for vulnerable groups. Geneva, World Health Organization, 1983.

50. Physical status: the use and interpretation of anthropometry. Report of a WHO Expert Committee. Geneva, World Health Organization, 1995 (WHO Technical Report Series, No. 854).

51. Jelliffe DB et al. Community nutritional assessment with special reference to less technically developed countries. Oxford, Oxford University Press, 1989.

52. Indicators for assessing iodine deficiency disorders and their control through salt iodization. Geneva, World Health Organization, 1994 (WHO/NUT/ 94.6).
53. Sommer A. Vitamin A deficiency and its consequences: a field guide to their detection and control, 3rd ed. Geneva, World Health Organization, 1995.

54. Indicators for assessing vitamin A deficiency and their application in monitoring and evaluating intervention programmes. Geneva, World Health Organization, 1996 (WHO/NUT/96.10).

55. El-Ghorab M. Clinical and biochemical assessment. In: Proceedings of the intercountry workshop on nutrition assessment in the Near East, Cairo, 1-5 November 1986. Rome, Food and Agriculture Organization, 1988 (ESN/MISC/ 88/2).

56. De Maeyer EM et al. Preventing and controlling iron deficiency anaemia through primary health care: a guide for health administrators and programme managers. Geneva, World Health Organization, 1989.

57. International Nutritional Anemia Consultative Group. Measurement of iron status. Washington DC, Nutrition Foundation, 1985.

58. Dallman PR. Diagnosis of anemia and iron deficiency: analytic and biological variations of laboratory tests. American journal of clinical nutrition, 1984, 39(6): 937-41.

59. Bieri JG, Tolliver TJ, Catignani GL. Simultaneous determination of alphatocopherol and retinol in plasma or red cells by high pressure liquid chromatography. American journal of clinical nutrition, 1979, 32(10):1143.

60. Assessment of fracture risk and its application to screening for postmenopausal osteoporosis. Report of a WHO Study Group. Geneva, World Health Organization, 1994 (WHO Technical Report Series, No. 843). 
61. Moussa WA et al. Feeding and weaning practices of infants and children less than two years at Cairo governorate. Bulletin of the National Institute of Nutrition, 1988, 8:82-100.

62. Moussa WA, Hegazy ME, Weber C. Energy and protein bioavailability of Egyptian rural preschooler diets: implications and application. In: Young KW et al., eds. Proceedings of the 14th International Congress of Nutrition, Seoul, Korea, 2025 August 1989. Seoul, South Korea, International Congress of Nutrition, 1991: 384.

63. Moussa WA. Weaning foods. Proceedings of the international conference on food for special dietary and medicinal uses, Cairo, Egypt. Bulletin of the National Nutrition Institute, 1990, 1:19-22.

64. Amine EK, al-Awadi F. Impact of mothers' education on infant feeding pattern and weaning practices in Kuwait. Ecology of food and nutrition, 1989, 24:29-36.

65. Al-Othaimeen Al, Villanueva BP, Devol EB. The present trend in infant feeding practices in Saudi Arabia. Food and nutrition bulletin, 1987, 9(2):62-8.

66. Harfouche JK, Mussaiger AO. Breastfeeding patterns: a review of studies in the Eastern Mediterranean Region. Alexandria, Egypt, World Health Organization Regional Office for the Eastern Mediterranean, 1993 (Technical Publication No. 4).

67. Omer MIA et al. Breastfeeding in the Sudan. Contemporary patterns and influencing factors. Journal of tropical pediatrics, 1987, 33(suppl. 3):1-12.

68. Amine EK, al-Awadi F. Infant feeding pattern and weaning practices in Kuwait. Journal of the Royal Society of Health, 1989, 109(5):178-80.

69. Moussa WA et al. The role of infection in causation of malnutrition in urban areas of Egypt with special reference to diarrheal disease. Journal of urban health, 1983, 44:7.

70. Noor $\mathrm{E}$ et al. Mother-toddler interaction and care-giving behaviour in an Egyptian semi-rural village. Atlanta, Georgia, Federation of American Societies for Experimental Biology, 1991.

71. Engle PL. Care and child nutrition. Report for International Congress on Nutrition, Rome 1992. New York, United Nations Children's Fund, 1992.

72. Moussa W. Dietary assessment and food consumption surveys. In: Proceedings of the inter-country workshop on nutrition assessment, Cairo, 1-5 November 1986. Rome, Food and Agriculture Organization, 1988 (ENS/MISC/88/2).

73. Den Hartog AP, van Staveren WA. Manual for social surveys on food habits and consumption in developing countries. Centre for Agricultural Publishing and Documentation, Wageningen, Holland, 1985.

74. Gibson RS. Principles of nutrition assessment. Oxford, Oxford University Press, 1990.

75. Pao EM, Cypel YS. Estimation of dietary intake. In: Ziegler EE, Filer LJ Jr, eds. Present knowledge in nutrition, 7th ed. Washington DC, ILSI Press, 1996:399_ 406.

76. Gómez F et al. Mortality in second and third degree malnutrition. Journal of tropical pediatrics, 1956, 2:77-83.

77. Waterlow JC. Classification and definition of protein-calorie malnutrition. British medical journal, 19723(826):566.

78. Obesity: preventing and managing the global epidemic. Report on a WHO consultation. Geneva, World Health Organization, 2000 (WHO Technical Report Series, No. 894). 
79. Garrow JS. Treat obesity seriously: a clinical manual. London, Churchill Livingstone, 1981:246-8 \& 301-4.

80. Guidelines for the development of a food and nutrition surveillance system for countries in the Eastern Mediterranean Region. Alexandria, World Health Organization Regional Office for the Eastern Mediterranean, 1989 (Technical Publication No. 13).

81. Egypt demographic and health survey. Cairo, National Population Council, Egypt, 2000.

82. Hassanyn SA et al. Food consumption pattern and nutrient intake among different population groups in Egypt. Cairo, National Nutrition Institute, 2000.

83. Shaheen FM, Tawfik AA. Intrahousehold food distribution among Egyptian families. Final report. Cairo, National Institute of Nutrition \& World Health Organization, 2000.

84. Yassai M, Kimiagar M. Nutritional anemia in urban pregnant women in Iran. Tehran, National Nutrition Institute, 1987.

85. Household budget survey. Tehran, Iran Statistical Centre, 1989.

86. Kimiagar M, Azizi F, Sami M. Goitre prevalence among school children in Iran. In: Agarwal MK, ed. Antihormones in health and disease. Satellite symposium of the 2nd European Congress of Endocrinology, Ljubljana, 1-6 July 1990: proceedings. Basel, Karger AG, 1991 (Frontiers of Hormone Research Vol. 19).

87. Rabiee F, Geissler C. Causes of malnutrition in young children in Gilan, Iran. Journal of tropical pediatrics, 1990, 36(4):165-70.

88. Smith MC, Zaidi S. Malnutrition in Iraqi children following the Gulf war: results of a national survey. Nutrition reviews, 1993, 51(3):74-8.
89. Takruri H, Hamdan MR. Food consumption pattern in the city of Amman and Irbid district: vitamin and mineral intakes. Emirates journal of agricultural science, 1989, 1:1-13.

90. Assessment of the nutritional status of preschool children in Jerash: a preliminary report. Amman, United Nations Children's Fund Regional Office for the Middle East, 1992.

91. Shaar KH, Shaar MA. The nutritional status of children of displaced families in Beirut. International journal of epidemiology, 1993, 22(2):348-57.

92. Situation analysis of women and children in the sultanate of Oman. Muscat, Oman, Ministry of Health \& United Nations Children's Fund, 1991.

93. Musaiger AO. Food consumption pattern of mothers in Oman (a preliminary study). Journal of the Royal Society of Health, 1991, 111(1):8-9.

94. Musaiger AO. Health and nutritional status of Omani families. Muscat, Oman, United Nations Children's Fund, 1992.

95. Carl S. lodine deficiency disorders in Pakistan. Islamabad, Pakistan, United Nations Children's Fund, 1985.

96. National nutrition survey. Islamabad, Pakistan, National Institute of Health, 1987.

97. Al-Othaimeen Al, Osman AK. Assessment of nutritional status of school children in Riyadh. Riyadh, United Nations Children's Fund Gulf Area Office, 1992.

98. Al Frayh AS, Bamgboye EA. The growth pattern of Saudi Arabian pre-school children in Riyadh to NCHS/CDC reference population. Journal of the Royal Society of Health, 1993, 113(5):234-9.

99. Ahmed AA, Ashkir AA. A study of the effects of mother's age, parity and birth interval on pregnancy outcomes in Moga- 
dishu. Mogadishu, Somali Family Health Care Association, 1987.

100. Nutrition survey of four areas in Mogadishu. Final report. Mogadishu, Urban Basic Services and Ministry of Health, 1988.

101. Al-Dhaher S. Infant and child feeding survey in the Syrian Arab Republic. Damascus, United Nations Children's Fund, 1987.

102. Mardini K. Nutritional assessment in Syria: lessons and experiences. In: Proceedings of the inter-country workshop on nutrition assessment in the Near East, Cairo, Egypt, 1-5 November 1986. Rome, Food and Agriculture Organization, 1988 (ESN/MISC/88/2).

103. The national nutrition survey in UAE: final report. Abu-Dhabi, Department of Preventive Medicine, Ministry of Health, 1992.
104. Bagenholm G, Kristiansson B, Nasher AA. Growth and malnutrition among preschool children in Democratic Yemen. Bulletin of the World Health Organization, 1988, 66(4):491-8.

105. The situation of children and women in the Republic of Yemen, 1992. Sana'a, United Nations Children's Fund, 1993.

106. Sudan emergency \& recovery information \& surveillance system. Khartoum, Nutrition Department \& Statistics Department, Ministry of Health, 1988, vols. 1-4.

107. Report on the FAO/WHO inter-country workshop on follow-up of the international conference on nutrition, (ICN). Cairo, Food and Agriculture Organization Regional Office for the Near East \& World Health Organization Regional Office for the Eastern Mediterranean, (WHO-EM/NUT/144-E/L). 